\title{
Web-Based Behavioral Intervention Utilizing Narrative Persuasion for HIV Prevention Among Chinese Men Who Have Sex With Men (HeHe Talks Project): Intervention Development
}

Meiqi Xin ${ }^{1}, \mathrm{PhD}$; Neil S Coulson ${ }^{2}, \mathrm{PhD}$; Crystal Li Jiang ${ }^{3}, \mathrm{PhD}$; Elizabeth Sillence ${ }^{4}, \mathrm{PhD}$; Andrew Chidgey ${ }^{5}$, BSc; Norman Nok Man Kwan ${ }^{6}$, BSS; Winnie W S Mak ${ }^{7}$, PhD; William Goggins ${ }^{1}$, SCD; Joseph Tak Fai Lau ${ }^{1}$, PhD; Phoenix Kit $\mathrm{Han} \mathrm{Mo}^{1}, \mathrm{PhD}$

${ }^{1}$ Centre for Health Behaviours Research, Jockey Club School of Public Health and Primary Care, The Chinese University of Hong Kong, Hong Kong, Hong Kong

${ }^{2}$ School of Medicine, University of Nottingham, Nottingham, United Kingdom

${ }^{3}$ Department of Media and Communication, City University of Hong Kong, Hong Kong, Hong Kong

${ }^{4}$ Department of Psychology, Northumbria University, Newcastle, United Kingdom

${ }^{5}$ AIDS Concern, Hong Kong, Hong Kong

${ }^{6}$ Health and Care Service Department, Hong Kong Red Cross, Hong Kong, Hong Kong

${ }^{7}$ Department of Psychology, The Chinese University of Hong Kong, Hong Kong, Hong Kong

\section{Corresponding Author:}

Phoenix Kit Han Mo, PhD

Centre for Health Behaviours Research

Jockey Club School of Public Health and Primary Care

The Chinese University of Hong Kong

202D, School of Public Health, Prince of Wales Hospital

30-32 Ngan Shing Street, Shatin, New Territories

Hong Kong

Hong Kong

Phone: 85222528765

Email:phoenix.mo@cuhk.edu.hk

\section{Abstract}

Background: In the era of potent antiretroviral therapy, a high level of condomless anal intercourse continues to drive increases in HIV incidence in recent years among men who have sex with men. Effective behavior change strategies for promoting HIV-preventive behaviors are warranted. Narrative persuasion is a novel health communication approach that has demonstrated its persuasive advantages in overcoming resistance to counterattitudinal messages. The efficacy of narrative persuasion in promoting health behavior changes has been well documented, but critical research gaps exist for its application to HIV prevention.

Objective: In this study, we aimed to (1) capitalize on narrative persuasion to design a web-based multisession intervention for reducing condomless anal intercourse among men who have sex with men in Hong Kong (the HeHe Talks Project) by following a systematic development process; and (2) describe the main components of the narrative intervention that potentially determine its persuasiveness.

Methods: Persuasive themes and subtopics related to reducing condomless anal intercourse were initially proposed based on epidemiological evidence. The biographic narrative interview method was used to elicit firsthand experiential stories from a maximum variation sample of local men who have sex with men with diverse backgrounds and experiences related to HIV prevention; different types of role models were established accordingly. Framework analysis was used to aggregate the original quotations from narrators into collective narratives under 6 intervention themes. A dedicated website was finally developed for intervention delivery.

Results: A series of video-based intervention messages in biographic narrative format (firsthand experiential stories shared by men who have sex with men) combined with topic-equivalent argumentative messages were produced and programmed into 6 intervention sessions. The 6-week intervention program can be automatically delivered and monitored online. 
Conclusions: We systematically created a web-based HIV prevention intervention derived from peer-generated stories. Strategies used to enhance the efficacy of the narrative intervention have been discussed within basic communication components. This paper describes the methods and experiences of the rigorous development of a narrative communication intervention for HIV prevention, which enables replication of the intervention in the future.

(J Med Internet Res 2021;23(9):e22312) doi: 10.2196/22312

\section{KEYWORDS}

narrative persuasion; firsthand experiential stories; online intervention; HIV prevention; sexual behavior; men who have sex with men

\section{Introduction}

\section{Men Who Have Sex With Men as an Important Target for HIV Prevention}

Although a steadily decreasing trend has been observed for the global HIV burden, the epidemic has continued to expand among men who have sex with men [1]. For example, in Hong Kong, HIV prevalence has increased to $6.54 \%$ among men who have sex with men in recent years, while the rate has remained lower than $0.1 \%$ in the general population [2]. Despite biomedical advances in antiretroviral therapy and growing access to care and treatment, there is a paradoxical rise in the HIV incidence rate among men who have sex with men that was found to be significantly associated with an increase in condomless anal intercourse $[3,4]$. The disproportionate risk is also fueled by a relatively low level of HIV testing [5,6]. More efforts are necessary to develop effective behavior change strategies for the promotion of HIV-preventive behaviors among this vulnerable population.

\section{Gaps in Communicating Persuasive Messages on HIV Prevention}

Although health communication is widely acknowledged as an important tool for HIV prevention [7], existing persuasive communications has failed to significantly stimulate behavior change [8]. Previous interventions drew heavily on classic health behavior change theories to improve cognitive determinants (eg, risk perceptions) [7]; however, such interventions are based on the assumption that message recipients are so-called rational individuals, and the influence of recipients' preexisting state in accepting and executing desirable behaviors are omitted $[9,10]$. Counterattitudinal messages, namely persuasive topics and arguments that differ from recipients' own values or beliefs [11], are largely used for health behavior promotion. For instance, interventions for HIV prevention are commonly developed to target high-risk groups who engage in unprotected sex or have a low intention to use condoms consistently. Recipients are prone to argue against advocated positions to protect their previously held values or beliefs [11,12], adhering to or even engaging in more of the discouraged behavior [13]. There has long been a need to overcome such resistance to persuasive messages about HIV prevention [14].

\section{Theoretical Mechanisms Underlying Narrative Persuasion}

Over the past decade, narrative persuasion has been recognized as a promising avenue for health communication [12]. A narrative refers to "a representation of connected events and characters that has an identifiable structure [15]." The traditional approach-argumentation-otherwise features expository and didactic communication, with a logical presentation of overt arguments and factual information in the form of reasons and evidence to put forth a claim $[12,15,16]$. The two communication styles are fundamentally different in terms of information processing. Instead of receiving carefully elaborated explicit persuasive arguments in argumentative communication [17], narrative processing typically involves engagement with narrative elements and identification with characters (ie, vicarious experience of characters' cognitive and emotional responses) as casually and chronologically related events unfold in a coherent manner $[16,18,19]$.

Narrative persuasion is grounded in both the Extended Elaboration Likelihood Model [18] and the Transportation-Imagery Model [20]; narrative persuasion has the advantage (over argumentation) of inhibiting negative responses to counterattitudinal messages because fewer targets are available for counterarguments, given its structure, with implicit persuasive content embedded in narrative elements; (2) there is less processing capacity and motivation to critically scrutinize core arguments that are presented in narrative format; and (3) identification with narrative characters facilitates psychological distancing from the recipients' initial story-inconsistent positions [16,18,19,21].

Remarkably, the incorporation of argumentative support further bolsters narrative persuasion [22,23], facilitating cognitive elaboration, rehearsal, and repetition, which leads to an enduring persuasive impact [18,24,25]. Prefacing argumentative messages by narrative messages could potentially predispose recipients to positively process and comprehend the overtly persuasive arguments [26-28]. Recipients could first shift from existing positions temporarily through engagement with the narrative messages, and fully assimilate the advocated positions into their own value structures through positive elaboration of the subsequent argumentation messages [18].

\section{Harnessing Narrative Persuasion for Behavioral Interventions}

Existing empirical evidence supports the efficacy of narrative interventions in promoting health behaviors relative to argumentation or null controls [29,30]. Relatively fewer studies have examined the effect of a combination of narrative and argumentative messages about cancer screening [31-33], diabetes self-care [34], and vaccination [35]; most were found to be more effective in changing the target behavior and its theoretical determinants than a single message format. 
Several studies [36-41] have applied narrative communication to HIV prevention, but there are some critical research gaps. First, most narratives took the form of fictional stories (eg, entertainment-education soap opera) that were scripted by researchers; its efficacy in improving HIV-preventive behaviors is controversial [36,37]. However, other narrative types, including experiential stories, have received little exploration. Second, some interventions involved multiple behavior change strategies (eg, condom distribution), and thus, made it difficult to isolate the specific effect of the narrative component [38]. Third, the majority of previous narrative interventions addressed heterosexual risk for HIV [39,40]; we suppose that efficacy of narrative interventions is higher among homosexual people because HIV prevention is more personally relevant to this population group, and personal relevance of a health topic can enhance narrative efficacy [41]. Finally, no studies have been conducted among Asian populations. More research on narrative persuasion in different contexts is warranted because shared stories inherently embody rich cultural information that shapes behaviors and responses to persuasive communication $[9,42]$.

\section{Utilizing Web-Based HIV Prevention Interventions for Men Who Have Sex With Men}

Web-based technology has been recognized as a powerful tool to efficiently reach target populations and deliver behavioral interventions to enhance responses to the ongoing HIV epidemic among men who have sex with men [6]. A recent meta-analysis [43] of 44 studies across 12 countries and regions found that eHealth interventions effectively reduced condomless anal intercourse, reduced multiple sex partnership, and increased the uptake of HIV testing among men who have sex with men.
Moreover, a considerable proportion of men who have sex with men actively use the internet for socializing and sex-seeking, which has been found to increase likelihood of condomless anal intercourse, and consequently, risk of HIV infection [44-46]. In Hong Kong, approximately $70 \%$ of men who have sex with men engage in sex-seeking online [47]. Hence, web-based interventions can seize the opportunity to promote HIV prevention among men who have sex with men at a crucial point when they tend to engage in risky sexual practices. In addition, Chinese men who have sex with men use the internet as the primary source of information about sexual health, HIV, and other sexually transmitted infections (STIs), and accept the use of eHealth in supporting their sexual health care [48].

In this study, we developed a web-based narrative intervention for HIV prevention among men who have sex with men in Hong Kong (the HeHe Talks Project) to deliver a series of video-based persuasive messages to reduce condomless anal intercourse. Biographic narratives (firsthand experiential stories shared by local men who have sex with men peers) were combined with topic-equivalent argumentative messages.

\section{Methods}

\section{Ethics and Procedure Overview}

Informed consent was obtained from all participants involved in this project. Ethical approval was obtained from Joint Chinese University of Hong Kong-New Territories East Cluster Clinical Research Ethics Committee (reference number 2014.274-T). A roadmap of the development procedure is presented in Figure 1 . 
Figure 1. Procedure for developing the narrative intervention program (HeHe Talks).

\begin{tabular}{|c|}
\hline $\begin{array}{l}\text { Identify persuasive themes/topics based on epidemiological evidence on } \\
\text { modifiable factors of condomless anal intercourse }\end{array}$ \\
\hline$v^{2}$ \\
\hline $\begin{array}{c}\text { Recruit a sample of narrators with diverse sociodemographic backgrounds } \\
\text { and experiences related to HIV prevention }\end{array}$ \\
\hline 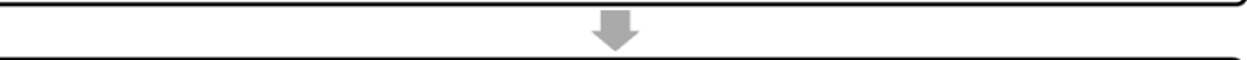 \\
\hline $\begin{array}{c}\text { Elicit firsthand experiential stories using biographic narrative interview } \\
\text { approach }\end{array}$ \\
\hline 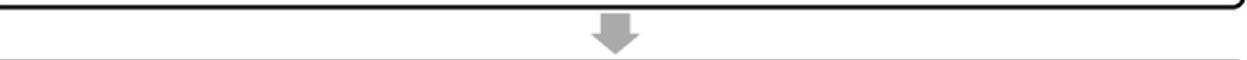 \\
\hline $\begin{array}{c}\text { Transcribe the videorecorded interview recordings and develop collective } \\
\text { narrative messages under } 6 \text { themes using framework analysis }\end{array}$ \\
\hline 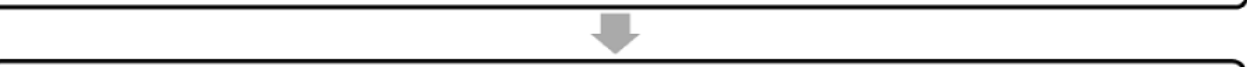 \\
\hline Edit the original videoclips and produce 6 narrative videos \\
\hline$\sqrt{2}+2$ \\
\hline $\begin{array}{l}\text { Develop the scripts of topic-equivalent argumentative messages and } \\
\text { produce } 6 \text { argumentative videos }\end{array}$ \\
\hline$\overline{2}$ \\
\hline $\begin{array}{l}\text { Establish a dedicated website to deliver the intervention and program the } \\
\text { intervention videos into } 6 \text { sessions }\end{array}$ \\
\hline
\end{tabular}

\section{Identifying Persuasive Themes and Subtopics}

We conducted a review of modifiable and significant predictors of HIV/STI infection and condomless anal intercourse among local men who have sex with men in publications and government documents to inform topic selection. Factors were categorized into cognitive (eg, risk perceptions), interpersonal (eg, sex partnership), contextual (eg, substance use), and sexual practice-specific (eg, group sex). In addition, it has been suggested that HIV testing behavior should be addressed simultaneously, given its significant relationship with condomless anal intercourse among Chinese men who have sex with men $[49,50]$. Six session themes were initially proposed: knowledge about HIV/STI, condom use and partnership, condom use and risky contexts, condom use and substance use, efficacy of condom use, and HIV testing (Multimedia Appendix 1).

Qualitative evidence was obtained by conducting a focus group discussion with 5 Hong Kong men who have sex with men (age: range 28-38 years). The focus group was led by a public health researcher and a health psychologist and was used to assess knowledge, views, and information needs regarding HIV prevention and condomless anal intercourse. Most interviewees had university-level educations and above (4/5) and had full-time jobs (4/5); 2 interviewees reported consistent condom use for anal sex, and 1 had engaged in substance use-facilitated anal sex in the previous 6 months.

This focus group informed refinement of the intervention topics. For example, the participants emphasized the phenomenon of "complacency about HIV" among local men who have sex with men (ie, that strong belief about antiretroviral therapy efficacy contributed to low-risk perceptions and high motivation to engage in condomless anal intercourse). Proposed intervention topics were sent to several HIV specialists; we further revised the topics based on their feedback. For example, they suggested focusing on drug use other than alcohol consumption to address reducing substance use-facilitated condomless anal intercourse; accordingly, the subtopic impact of alcohol use on condomless anal intercourse was removed.

\section{Recruiting Narrators and Operationalizing the Role Models}

The Sabido entertainment-education strategy [25] was applied to establish 3 types of role models: (1) positive characters, who engage in consistent condom use while having anal intercourse and undergo regular HIV testing, and consequently, maintain sexual health; (2) negative characters, who engage in condomless anal intercourse and do not regularly undergo HIV testing, and are negatively affected (eg, infected with HIV or STI); and (3) transitional characters, who once engaged in risky sexual behaviors and suffered negative consequences and then adopted more positive attitudes and behaviors. Role modeling has been adopted in previous entertainment-education programs for HIV prevention [37,39]. Maximum variation sampling was used to recruit 2 to $3 \mathrm{HIV}$-positive and 6 to $7 \mathrm{HIV}$-negative narrators with different experiences and backgrounds [51].

Criteria for all narrators were (1) men who have sex with men; (2) age $\geq 18$ years; (3) Hong Kong residents; (4) able to speak Cantonese fluently; and (5) of sufficient mental and physical capability to take part in a 2-hour interview. Criteria for HIV-positive narrators were (1) confirmed or high probability 
of having acquired HIV by sexual transmission; (2) encountered negative experiences due to living with HIV; (3) once or currently undergoing antiretroviral treatment; and (4) having engaged in any condomless anal intercourse with male sex partners prior to the diagnosis. Criteria for HIV-negative narrators were (1) having undergone at least 1 HIV test in the previous year, with the most recent test having yielded a negative result; (2) consistently used condoms with male sex partners (in every sexual encounter in the previous year); and (3) having positive perceptions about condom use for HIV prevention. Prospective narrators were nominated and approached by the research team and a collaborating nongovernmental organization (AIDS Concern). A survey was administered to establish their eligibility and to create a profile for each individual, with background information (eg, age and sexual partnership) and specific experiences related to HIV prevention (eg, contracting HIV/STI infections, engaging in condomless anal intercourse).

\section{Developing Persuasive Messages in Narrative and Argumentation Formats}

Biographic-Narrative Interpretive Method [52,53] was employed to elicit narratives for the development of health promotion messages. A semistructured interview guide was drafted around the proposed topics and tailored to each narrator's profile. Two interviewers (MX and NK) and a professional camera operator were involved in the individual interviews with each of the selected narrators. One of the interviewers (NK) was a senior practitioner from the collaborating nongovernmental organization who had rich experience in providing community support services to local men who have sex with men; he took a leading role in the narrative interviews and preinterview negotiations, particularly with HIV-positive narrators, to ensure that the questions were delivered in a comfortable and respectful manner.

Interviewers first briefed the narrator on interview procedures and established rapport. Individual interviews started with a single question that was thematically or temporally focused, to elicit narratives of personal experiences, such as life after being diagnosed as HIV positive or an occasion of safe sex practices at a gay venue. Narrators were free to tell their story in the manner of their choosing (to provoke the narration within their own system of relevancy), and interviewers merely provided nondirectional facilitative support. Keyword notes were also taken to document the topics of interest arising in the original narrative, which helped inform follow-up questions for additional narrative to enrich the overarching story. After narrative-seeking questions, interviewers asked additional questions about topics that had not been raised or for purposes other than narrative extraction (eg, to make a persuasive appeal to the audience).

Videorecordings of the interviews were transcribed. Framework analysis was conducted to develop themed narrative messages using NVivo (version 11, QSR International) in 5 steps [54]: (1) familiarizing: carefully reading the transcripts and observational notes to gain a comprehensive understanding of the data; (2) framing: devising and refining a coding framework drawn on both predefined and emergent themes and subtopics; (3) indexing: systemically sorting original narrative quotations within the thematic framework; (4) charting: grouping indexed narratives from different narrators for each coded subtopic; (5) mapping: aggregating subtopics and corresponding quotations in a coherent manner under each of the 6 session themes to generate collective narrative messages. For each subtopic, argumentative messages were drafted based on the narrative content, by presenting didactic statements, factual claims, logical reasons, and statistical evidence.

\section{Producing Intervention Videos and a Web-Based Delivery Platform}

The videorecordings of the original narratives were segmented and re-organized to create 6 videos for the themes derived from the framework analysis. A background profile was presented for each narrator at first appearance in the videos; persuasive appeals from 1 or 2 narrators were used as epilogues. Videos were sent to the narrators to get their approval. Three male speakers (a nongovernmental organization staff and 2 research assistants) were invited to deliver scripted, videorecorded argumentative messages for each theme. Supplementary material, such as openings, subtitles, images, and background music, were added, and the finalized videos were programmed into 6 intervention sessions. Each included 2 videos with narrative (15-20 minutes) and argumentative (8-10 minutes) messages and a postvideo quiz set to enhance participants' dedication to intervention content. The narrative videos were longer than the topic-equivalent argumentative videos due to the inherent natures of storytelling (ie, portraying a series of events) and argumentation (ie, listing facts and evidence). A dedicated website was developed to deliver intervention sessions automatically, and a content management system was established for real-time monitoring of engagement in the program.

\section{Results}

\section{Narrator Characteristics}

A total of 36 men who have sex with men were screened, and 9 men were selected as narrators (Table 1). Two men, who had been diagnosed as HIV-positive 3 years prior, served as negative role-model narrators. The other men had recent HIV-negative test results (within 1 year): 3 men had never engaged in condomless anal intercourse with a male sex partner in their lifetime, and thus, served as positive role-model narrators; 4 men had once engaged in condomless anal intercourse but had consistently used condoms in the past year, and thus, served as transitional role-model narrators.

Narrators had varying sexual practices (Table 2): 3 had regular partners, and 5 had casual partners; 4 had engaged in both insertive (taking a top role) and receptive (taking a bottom role) anal intercourse; 6 had engaged in casual fun - anal intercourse with casual sex partners in collective sex environments (eg, gay saunas, group sex events [55]); 5 had engaged in chem-sex - anal intercourse while under the influence of psychotropic substances (eg, methamphetamine). 
Table 1. Background characteristics of the 9 narrators.

\begin{tabular}{|c|c|c|c|c|c|c|}
\hline $\begin{array}{l}\text { Narrator } \\
\text { (role model type) }\end{array}$ & $\begin{array}{l}\text { Age } \\
\text { (years) }\end{array}$ & Employment & Years as member ${ }^{\mathrm{a}}$ & HIV $^{\mathrm{b}}$ status & $\begin{array}{l}\text { History of other STIs } \\
\text { (type) }\end{array}$ & $\begin{array}{l}\text { Type of HIV testing venues } \\
\text { visited }\end{array}$ \\
\hline A (negative) & 24 & Unemployed & Not disclosed & Positive & Yes (syphilis) & Community organization \\
\hline B (negative) & 24 & Unemployed & $>10$ & Positive & No & Public social hygiene clinic \\
\hline $\mathrm{C}$ (transitional) & 30 & Full-time & $>10$ & Negative & $\begin{array}{l}\text { Yes (urethritis, pubic } \\
\text { lice) }\end{array}$ & $\begin{array}{l}\text { Public social hygiene clinic; } \\
\text { community organization }\end{array}$ \\
\hline $\mathrm{D}$ (positive) & 38 & Full-time & $>10$ & Negative & No & $\begin{array}{l}\text { Community organization; } \\
\text { private clinic }\end{array}$ \\
\hline E (transitional) & 26 & Full-time & $>5$ & Negative & No & $\begin{array}{l}\text { Public social hygiene clinic; } \\
\text { community organization }\end{array}$ \\
\hline F (transitional) & 36 & Full-time & $>10$ & Negative & Yes (syphilis) & Community organizations \\
\hline $\mathrm{G}$ (positive) & 30 & $\begin{array}{l}\text { Full-time; } \\
\text { Part-time }\end{array}$ & $>10$ & Negative & No & $\begin{array}{l}\text { Public social hygiene clinic; } \\
\text { community organization }\end{array}$ \\
\hline $\mathrm{H}$ (transitional) & 32 & Full-time & $>10$ & Negative & No & Community organization \\
\hline I (positive) & 22 & Student & $>5$ & Negative & No & Community organization \\
\hline
\end{tabular}

${ }^{\text {a }}$ Period between self-identification as homosexual or bisexual and involvement in the local community of men who have sex with men.

${ }^{b}$ HIV: human immunodeficiency virus.

${ }^{\mathrm{c}}$ STIs: sexually transmitted infections.

Table 2. Characteristics of the 9 narrators related to sexual practices (ie, anal intercourse with male sex partners prior to diagnosis or in the past year).

\begin{tabular}{llllll}
\hline $\begin{array}{l}\text { Narrator } \\
\text { (role model type) }\end{array}$ & Sexual partnership & Sexual role & Consistent condom use ${ }^{\mathrm{a}}$ & ${\text { Casual fun }{ }^{\mathrm{b}} \text { (venue) }}$ & Chem-sex $^{\mathrm{c}}\left(\mathrm{drug}_{\text {type }}{ }^{\mathrm{d}}\right.$ ) \\
\cline { 5 - 6 } A (negative) & Not recorded & Not recorded & No & No & No \\
B (negative) & Not recorded & Not recorded & No & Yes (gay sauna; private party) & $\begin{array}{l}\text { Yes (meth, g water, foxy, } \\
\text { rush poppers) }\end{array}$ \\
C (transitional) & Regular; casual & Top; bottom & Yes (recent) & Yes (gay sauna; private party) & Yes (rush poppers) \\
D (positive) & Regular & Top & Yes (lifetime) & No & No \\
E (transitional) & Casual & Top; bottom & Yes (recent) & Yes (gay sauna) & Yes (meth, g water, foxy) \\
F (transitional) & Casual & Bottom & Yes (recent) & Yes (gay sauna) & Yes (meth, foxy, ecstasy) \\
G (positive) & Regular & Top & Yes (lifetime) & No & Yes (rush poppers) \\
H (transitional) & Regular; casual & Top; bottom & Yes (recent) & Yes (gay sauna) & No \\
I (positive) & Casual & Top; bottom & Yes (lifetime) & Yes (gay sauna) & No \\
\hline
\end{tabular}

${ }^{\mathrm{a}}$ The response recent referred to having once engaged in any condomless anal intercourse in lifetime but consistently using condoms within the past year; the response lifetime referred to having never engaged in condomless anal intercourse in lifetime.

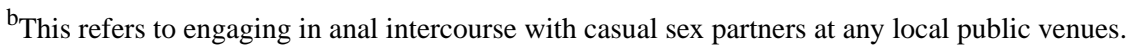

${ }^{\mathrm{c}}$ This refers to taking illicit drugs during or prior to anal intercourse.

${ }^{\mathrm{d}}$ Meth, g water, foxy (ie, foxy methoxy), rush poppers, and ecstasy as slang for methamphetamine; gamma hydroxybutyrate/gamma butyrolactone; 5-methoxy-N,N-diisopropyltryptamine; inhalant alkyl nitrites; and 3,4-methylenedioxy-methamphetamine, respectively, were reported.

\section{Topics and Contents of Persuasive Messages}

There are 6 intervention sessions in total (Table 3); all sessions start with persuasive messages in the narrative format. The first session (A New Era of HIV Prevention) introduces the outcomes of HIV infection in the era of potent antiretroviral therapy. The HIV-positive peers narrate their experiences of receiving a diagnosis and living with HIV, with a focus on the severity of infections, negative influences on physical health and personal life, and co-infections with other STIs. The second session (Partnership and Protected Sex) includes experiences of condom use with different types of sexual partners, including actively negotiating condom use and making sexual decisions, resisting sexual pressure from partners, and balancing emotional relationships and safe sex practices. The third session (Casual Fun and Protected Sex) presents both obstacles to condom use experienced in high-risk contexts (eg, dark rooms in gay saunas and group sex parties) and practical skills for coping with unintentional condomless anal intercourse. The fourth session (Chem-Sex) focuses on potential exposure to psychotropic substances at local gay venues, negative influences of substance use on sexual practices and physical health, and problems related 
to drug addiction. The fifth session (Efficacy of Condom Use) focuses on consistent and correct condom use for anal intercourse as well as its efficacy in preventing STIs. The last session (HIV Testing) includes experiences of undergoing HIV testing and counseling at different service sites and emphasizes the importance of regular testing while adhering to safe sex practices. Each narrative video ends with narrators appealing to the listeners. For example, the first session includes a positive message from a HIV-positive narrator; he talks about gradually accepting and recognizing his infection status, adhering to treatment, and having hope for a new future.

Table 3. An overview of topics in the narrative messages for each intervention session.

\begin{tabular}{ll}
\hline Themes and subtopics of narrative messages & Message sources (narrator and \\
\hline Session 1: A New Era of HIV Prevention & \\
1. HIV diagnosis & A (negative) and B (negative) \\
2. Life impact of living with HIV & A (negative) and B (negative) \\
3. Problems encountered during HIV treatment & A (negative) and B (negative) \\
4. Co-infection with other sexually transmitted diseases & A (negative)
\end{tabular}

\section{Session 2: Partnership and Protected Sex}

1. Active communication about condom use and assessment of partner(s)' HIV risk

2. Assertive responses to unwanted condomless sex

3. Barriers to condom use when in an emotional relationship

\section{Session 3: Casual Fun and Protected Sex}

1. Risk of condomless sex with casual partners and norm about condom use at gay saunas

2. Unintentional condomless sex encountered during casual fun

3. Contextual risk of group sex parties

\section{Session 4: Chem-Sex}

1. Impact of drug abuse on sexual practices

2. Impact of drug abuse on other health outcomes

3. Exposure to drugs when seeking sex

4. Drug addiction

\section{Session 5: Efficacy of Condom Use}

1. Protective efficacy of condom use

2. Correct condom use

3. Consistent condom use

\section{Session 6: HIV Testing}

1. Local HIV testing services

2. Regular HIV testing
$\mathrm{D}$ (positive), C (transitional), and $\mathrm{E}$ (transitional)

A (negative), D (positive), G (positive), C (transitional), and E (transitional)

$\mathrm{D}$ (positive), G (positive), C (transitional), and E (transitional)

B (negative), D (positive), I (positive), C (transitional), E (transitional), and F (transitional)

B (negative), D, I (positive), C (transitional), E (transitional), and F (transitional)

B (negative), D (positive), C (transitional), and $\mathrm{H}$ (transitional)

B (negative), E (transitional), F (transitional), and $\mathrm{H}$ (transitional)

B (negative), D (positive), C (transitional), E (transitional), and F (transitional)

B (negative), D (positive), G (positive), I (positive), C (transitional), E (transitional), and $\mathrm{F}$ (transitional)

$\mathrm{B}$ (negative), E (transitional), and F (transitional)

D (positive), G (positive), I (positive), and E (transitional)

D (positive), I (positive), C (transitional), and E (transitional)

D (positive), G (positive), C (transitional), F (transitional), and G (transitional)

D (positive), G (positive), C (transitional), E (transitional), and $\mathrm{H}$ (transitional)

A (negative), G (positive), I (positive), C (transitional), and $\mathrm{H}$ (transitional)
The topic-equivalent argumentative messages are delivered after narratives. For example, for the subtopic Consistent condom use (in Session 5), the narrative presents experiences of condomless sex and STI infections from an HIV-positive narrator, and the argumentative message is

If the sexual partner is HIV-positive, one could get infected through only a "single" episode of unprotected sexual encounter, ...research studies demonstrated that there was no significant difference in HIV risk between men who have sex with men who "inconsistently use condoms" and those who "have never ever used condoms."

After videos, a quiz question is asked. For example, "According to the video messages, what type of immune cell was primarily attacked by HIV?" One correct response options ("CD4 cell") and 2 false response options ("CD3 cell" and "CD8 cell") are provided. Feedback and reinforcement are not given after the quiz, although users can return to the video during and after the quiz. 


\section{Web-Based Intervention Program}

The program website can deliver the intervention automatically in a standardized manner: the 6 intervention sessions can be released sequentially on a weekly basis, and each session is accessible upon completion of the preceding session. Users can be assigned a unique password-protected account to access intervention content within a 6-week period, and activities are automatically recorded (eg, the dates and time of completing an intervention video). The program can also send out reminders when a new session is released, or users fail to engage in any activity for 2 to 3 weeks.

\section{Discussion}

\section{General}

We developed a theory-based and evidence-based narrative communication intervention for HIV prevention among men who have sex with men. The communication strategies used by this intervention program to enhance the potential narrative efficacy can be systematically discussed within the 4 basic components of health communication: message, source, recipient, and channel [12].

\section{Message}

Narratives took the form of firsthand experiential stories, in contrast to commonly used fictional stories [12]. To maintain the authenticity of personal experience narratives, which is the key to exploiting its advantages (ie, being perceived as credible, evoking high engagement and inhibiting counterarguing) over those of professionally generated stories in persuasion $[15,56]$, we used well-developed methods for biographic narrative interviews to obtain stories [52]. The narrators were always given the space and time to narrate without any interruption; while the interviewers performed active listening by intermittently giving prompts, with nonverbal posture or empathetic and unobtrusive mirroring of the emotions expressed, throughout the storytelling. In addition, the intervention messages were produced by directly extracting biographic accounts from the videorecorded interview. Narratives conveyed in first-person are more effective than third-person narratives for STI prevention [35], because an individual is more likely to mentally embody characters' perspectives (ie, identification with characters) [57]. These strategies also strengthened the incorporation of cultural codes including visual presentations, language, and idioms that could heighten narrative engagement [58]. Furthermore, this narrative intervention featured subsequent provision of argumentative support. The argumentative messages were developed to match the themes and subtopics of the narrative messages, to reinforce the predisposition created by narrative persuasion but to avoid provoking counterargument [18].

\section{Source}

Collective narratives were extracted from a maximum variation sample of local men who have sex with men peers in this study to improve the comprehensiveness of persuasive content [15] and appeal to different audience segments [25]. The diversity of narrators allowed 3 types of characters to be established. The transitional role model was utilized the most in order to reduce selective avoidance of counterattitudinal messages about HIV prevention [19] and increase perceived homophily and realism of the characters, and thus, facilitate narrative processing [18], and enhance self-efficacy in changing risky sexual behaviors [59]. Positive and negative role models were also used to reinforce the consistency of condom use. Moreover, biographic narratives were a representation of the narrators' views of their own life-course, beliefs, interpretative schemata, and principles of judgement [52], which provided authentic and comprehensive portrayals of the characters, and in particular, avoided fostering negatively biased images of HIV-positive peers. For instance, the narrators with a history of HIV/STI shared their experiences of infection and risky sexual encounters as well as how they strived to adhere to treatments and improve their HIV-preventive behaviors.

\section{Recipients}

The targeted recipients are Chinese men who have sex with men, a highly marginalized community where members are strongly connected to each other [60]; social norms and community involvement have been found to be positively associated with their HIV-preventive behaviors [61,62]. To produce culturally authentic messages and engage the recipients [9], members of the local men who have sex with men community were actively involved throughout the intervention development, including determining persuasive topics, screening eligible narrators, assisting in narrative interviews, and generating and delivering intervention messages. Such participatory strategies can be applicable to other similar contexts where the community tend to share motives and values regarding health behavior.

\section{Channel}

The intervention comprises web-based videos. Video-based narratives have demonstrated strengths in building affection, facilitating identification with characters, and message elaboration, thereby promoting behavior changes [29,63,64]. Narrators' ability to organize and articulate stories in videorecorded interviews were carefully evaluated during the recruitment. The web-based delivery platform allows navigation of the content at the user's own pace without the presence of researchers; users are less likely to mask emotional responses and experience greater immersion when they view narratives alone [56].

\section{Conclusions}

In response to the call for innovative health communication approaches for HIV prevention, this paper describes the scientific rationale and rigorous procedure of applying narrative persuasion to promote HIV-preventive behaviors among men who have sex with men. This web-based narrative communication intervention can be easily replicated in other contexts and can be incorporated into comprehensive HIV prevention services. 


\section{Acknowledgments}

This study was funded by the University Grants Committee of Hong Kong 2015-2016 General Research Fund (reference 14612615). We would like to express our heartfelt gratitude to all the narrators and participants in this project.

\section{Conflicts of Interest}

None declared.

\section{Multimedia Appendix 1}

A summary of factors of HIV/STI infection and related behaviors among men who have sex with men in Hong Kong. [DOCX File, 34 KB-Multimedia Appendix 1]

\section{References}

1. Beyrer C, Baral SD, van Griensven F, Goodreau SM, Chariyalertsak S, Wirtz AL, et al. Global epidemiology of HIV infection in men who have sex with men. Lancet 2012 Jul 28;380(9839):367-377 [FREE Full text] [doi:

10.1016/S0140-6736(12)60821-6] [Medline: 22819660]

2. HIV surveillance report 2017 update. The Virtual AIDS Office of Hong Kong. Hong Kong: Hong Kong Department of Health; 2018. URL: https://www.aids.gov.hk/english/surveillance/sur report/hiv17.pdf [accessed 2021-05-31]

3. Phillips AN, Cambiano V, Nakagawa F, Brown AE, Lampe F, Rodger A, et al. Increased HIV incidence in men who have sex with men despite high levels of ART-induced viral suppression: analysis of an extensively documented epidemic. PLoS ONE 2013 Feb 15;8(2):e55312. [doi: 10.1371/journal.pone.0055312]

4. Recommended HIV/AIDS strategies for Hong Kong (2017-2021). Hong Kong Advisory Council on AIDS. URL: http:/ /www.aca.gov.hk/english/strategies/pdf/strategies17-21.pdf [accessed 2021-05-31]

5. Campbell CK, Lippman SA, Moss N, Lightfoot M. Strategies to increase HIV testing among MSM: a synthesis of the literature. AIDS Behav 2018 Aug 17;22(8):2387-2412. [doi: 10.1007/s10461-018-2083-8] [Medline: 29550941]

6. Beyrer C, Baral SD, Collins C, Richardson ET, Sullivan PS, Sanchez J, et al. The global response to HIV in men who have sex with men. Lancet 2016 Jul 09;388(10040):198-206. [doi: 10.1016/S0140-6736(16)30781-4] [Medline: 27411880]

7. Storey D, Seifert-Ahanda K, Andaluz A, Tsoi B, Matsuki J, Cutler B. What is health communication and how does it affect the HIV/AIDS continuum of care? a brief primer and case study from New York City. J Acquir Immune Defic Syndr 2014 Aug 15;66 Suppl 3:S241-S249. [doi: 10.1097/QAI.0000000000000243] [Medline: 25007193]

8. Albarracín D, McNatt PS, Klein CTF, Ho RM, Mitchell AL, Kumkale GT. Persuasive communications to change actions: an analysis of behavioral and cognitive impact in HIV prevention. Health Psychol 2003 Mar;22(2):166-177 [FREE Full text] [doi: 10.1037//0278-6133.22.2.166] [Medline: 12683737$]$

9. Airhihenbuwa CO, Obregon R. A critical assessment of theories/models used in health communication for HIV/AIDS. J Health Commun 2000 Feb 02;5 Suppl(sup1):5-15. [doi: 10.1080/10810730050019528] [Medline: 11010357 ]

10. Norman P, Conner M. The theory of planned behaviour and binge drinking: assessing the moderating role of past behaviour within the theory of planned behaviour. Br J Health Psychol 2006 Feb;11(Pt 1):55-70. [doi: 10.1348/135910705X43741] [Medline: 16480555]

11. Slater M. Involvement as goal-directed strategic processing. In: The Persuasion Handbook: Developments in Theory Practice. Thousand Oaks: Sage Publications; 2002:175-194.

12. Hinyard LJ, Kreuter MW. Using narrative communication as a tool for health behavior change: a conceptual, theoretical, and empirical overview. Health Educ Behav 2007 Oct 30;34(5):777-792. [doi: 10.1177/1090198106291963] [Medline: 17200094]

13. Brehm S, Brehm J. Psychological Reactance: A Theory of Freedom and Control. New York: Academic Press; 2013.

14. Campbell RG, Babrow AS. The role of empathy in responses to persuasive risk communication: overcoming resistance to HIV prevention messages. Health Commun 2004;16(2):159-182. [doi: 10.1207/S15327027HC1602 2] [Medline: 15090283]

15. Kreuter MW, Green MC, Cappella JN, Slater MD, Wise ME, Storey D, et al. Narrative communication in cancer prevention and control: a framework to guide research and application. Ann Behav Med 2007 Jun;33(3):221-235. [doi: 10.1007/BF02879904] [Medline: 17600449]

16. Bilandzic H, Busselle R. Narrative persuasion. In: Dillard JP, Shen L, editors. The Persuasion Handbook: Developments in Theory Practice second ed. Thousand Oaks: Sage Publications; 2013:200-219.

17. O'Keefe D. The elaboration likelihood model. In: Dillard JP, Shen L, editors. The Persuasion Handbook: Developments in Theory Practice second ed. Thousand Oaks: Sage Publications; 2013:137-149.

18. Slater MD, Rouner D. Entertainment-education and elaboration likelihood: understanding the processing of narrative persuasion. Commun Theory 2002 May;12(2):173-191. [doi: 10.1111/j.1468-2885.2002.tb00265.x]

19. Moyer-Guse E. Toward a theory of entertainment persuasion: Explaining the persuasive effects of entertainment-education messages. Communication theory 2008;18(3):407-425. [doi: 10.1111/j.1468-2885.2008.00328.x] 
20. Green MC, Brock TC. The role of transportation in the persuasiveness of public narratives. J Pers Soc Psychol 2000 Nov;79(5):701-721. [doi: 10.1037//0022-3514.79.5.701] [Medline: 11079236 ]

21. Cohen J. Defining identification: a theoretical look at the identification of audiences with media characters. Mass Communication and Society 2001 Aug;4(3):245-264. [doi: 10.1207/S15327825MCS0403_01]

22. O'Keefe DJ. Justification explicitness and persuasive effect: a meta-analytic review of the effects of varying support articulation in persuasive messages. Argumentation and Advocacy 2017 Dec 18;35(2):61-75. [doi: 10.1080/00028533.1998.11951621]

23. de Graaf A, Sanders J, Hoeken H. Characteristics of narrative interventions and health effects: a review of the content, form, and context of narratives in health-related narrative persuasion research. Rev Commun Res 2016;4:88-131. [doi: 10.12840/issn.2255-4165.2016.04.01.011]

24. Igartua J, Vega Casanova J. Identification with characters, elaboration, and counterarguing in entertainment-education interventions through audiovisual fiction. J Health Commun 2016 Jan 05;21(3):293-300. [doi: 10.1080/10810730.2015.1064494] [Medline: 26166213]

25. Singhal A, Rogers E. Entertainment-Education: A Communication Strategy for Social Change. Mahwah, New Jersey: Routledge; 1999.

26. Moyer-Gusé E, Jain P, Chung AH. Reinforcement or reactance? examining the effect of an explicit persuasive appeal following an entertainment-education narrative. J Commun 2013 Mar 20;62(6):1010-1027. [doi:

10.1111/j.1460-2466.2012.01680.x]

27. Lane R, Miller AN, Brown C, Vilar N. An examination of the narrative persuasion with epilogue through the lens of the elaboration likelihood model. Commun Q 2013 Sep;61(4):431-445. [doi: 10.1080/01463373.2013.799510]

28. Oh HJ, Larose R. Tell me a story about healthy snacking and I will follow: comparing the effectiveness of self-generated versus message-aided implementation intentions on promoting healthy snacking habits among college students. Health Commun 2015 Sep 25;30(10):962-974. [doi: 10.1080/10410236.2014.910289] [Medline: 25256795]

29. Shen F, Sheer VC, Li R. Impact of narratives on persuasion in health communication: a meta-analysis. J Advert 2015 May 05;44(2):105-113. [doi: 10.1080/00913367.2015.1018467]

30. Perrier M, Martin Ginis KA. Changing health-promoting behaviours through narrative interventions: a systematic review. J Health Psychol 2018 Dec;23(11):1499-1517. [doi: 10.1177/1359105316656243] [Medline: 27387514]

31. Dillard AJ, Fagerlin A, Dal Cin S, Zikmund-Fisher BJ, Ubel PA. Narratives that address affective forecasting errors reduce perceived barriers to colorectal cancer screening. Soc Sci Med 2010 Jul;71(1):45-52 [FREE Full text] [doi: 10.1016/j.socscimed.2010.02.038] [Medline: 20417005]

32. McGregor LM, von Wagner C, Vart G, Yuen WC, Raine R, Wardle J, et al. The impact of supplementary narrative-based information on colorectal cancer screening beliefs and intention. BMC Cancer 2015 Mar 21;15(1):162 [REE Full text] [doi: 10.1186/s12885-015-1167-3] [Medline: 25884168]

33. McQueen A, Caburnay C, Kreuter M, Sefko J. Improving adherence to colorectal cancer screening: a randomized intervention to compare screener vs. survivor narratives. J Health Commun 2019 Mar 29;24(2):141-155 [FREE Full text] [doi: 10.1080/10810730.2019.1587109] [Medline: 30924402]

34. Campbell T, Dunt D, Fitzgerald JL, Gordon I. The impact of patient narratives on self-efficacy and self-care in Australians with type 2 diabetes: stage 1 results of a randomized trial. Health Promot Int 2015 Sep 28;30(3):438-448. [doi: 10.1093/heapro/dat058] [Medline: 23985247]

35. Nan X, Dahlstrom MF, Richards A, Rangarajan S. Influence of evidence type and narrative type on HPV risk perception and intention to obtain the HPV vaccine. Health Commun 2015 Jul 25;30(3):301-308. [doi: 10.1080/10410236.2014.888629] [Medline: 25061715]

36. Downs JS, Murray PJ, Bruine de Bruin W, Penrose J, Palmgren C, Fischhoff B. Interactive video behavioral intervention to reduce adolescent females' STD risk: a randomized controlled trial. Soc Sci Med 2004 Oct;59(8):1561-1572. [doi: 10.1016/j.socscimed.2004.01.032] [Medline: 15279915]

37. Jones R, Hoover DR, Lacroix LJ. A randomized controlled trial of soap opera videos streamed to smartphones to reduce risk of sexually transmitted human immunodeficiency virus (HIV) in young urban African American women. Nurs Outlook 2013;61(4):205-215.e3 [FREE Full text] [doi: 10.1016/j.outlook.2013.03.006] [Medline: 23743482]

38. The CDC AIDS Community Demonstration Projects Research Group. Community-level HIV intervention in 5 cities: final outcome data from the CDC AIDS Community Demonstration Projects. Am J Public Health 1999 Mar;89(3):336-345. [doi: 10.2105/ajph.89.3.336] [Medline: 10076482]

39. Vaughan PW, Rogers EM, Singhal A, Swalehe RM. Entertainment-education and HIV/AIDS prevention: a field experiment in Tanzania. J Health Commun 2000 Feb 02;5 Suppl(sup1):81-100. [doi: 10.1080/10810730050019573] [Medline: 11010359]

40. Zhang J, Chen GM, Chock TM, Wang Y, Ni L, Schweisberger V. A psychophysiological study of processing HIV/AIDS public service announcements: the effects of novelty appeals, sexual appeals, narrative versus statistical evidence, and viewer's sex. Health Commun 2016 Jul 07;31(7):853-862. [doi: 10.1080/10410236.2015.1012629] [Medline: 26642917]

41. Zhang J, Chock TM, Chen GM, Schweisberger V, Yi W. Persuasiveness of HIV/AIDS public service announcements as a function of argument quality, personal relevance, and evidence form. Soc Behav Pers 2014 Nov 18;42(10):1603-1612. [doi: $10.2224 / \mathrm{sbp} .2014 .42 .10 .1603$ ] 
42. Green M, Brock T. The narrative integration of personal and collective identity in social movements. In: Jacobs RN, editor. Narrative Impact: Social and Cognitive Foundations. Mahwah, NJ: Lawrence Erlbaum Associates; 2002:205-228.

43. Xin M, Viswanath K, Li AY, Cao W, Hu Y, Lau JT, et al. The effectiveness of electronic health interventions for promoting HIV-preventive behaviors among men who have sex with men: meta-analysis based on an integrative framework of design and implementation features. J Med Internet Res 2020 May 25;22(5):e15977 [FREE Full text] [doi: 10.2196/15977] [Medline: 32449685]

44. Zou H, Fan S. Characteristics of men who have sex with men who use smartphone geosocial networking applications and implications for HIV interventions: a systematic review and meta-analysis. Arch Sex Behav 2017 May;46(4):885-894. [doi: 10.1007/s10508-016-0709-3] [Medline: 27043837]

45. Pan S, Xu J, Han X, Zhang J, Hu QH, Chu ZX, et al. Internet-based sex-seeking behavior promotes HIV infection risk: a 6-year serial cross-sectional survey to MSM in Shenyang, China. Biomed Res Int 2016;2016:2860346-2860346 [FREE Full text] [doi: 10.1155/2016/2860346] [Medline: 28105415]

46. Lewnard JA, Berrang-Ford L. Internet-based partner selection and risk for unprotected anal intercourse in sexual encounters among men who have sex with men: a meta-analysis of observational studies. Sex Transm Infect 2014 Jun 11;90(4):290-296. [doi: 10.1136/sextrans-2013-051332] [Medline: 24518249]

47. Kwan TH, Lee SS. Bridging awareness and acceptance of pre-exposure prophylaxis among men who have sex with men and the need for targeting chemsex and HIV testing: cross-sectional survey. JMIR Public Health Surveill 2019 Jul 03;5(3):e13083 [FREE Full text] [doi: 10.2196/13083] [Medline: $\underline{31271148]}$

48. Muessig KE, Bien CH, Wei C, Lo EJ, Yang M, Tucker JD, et al. A mixed-methods study on the acceptability of using eHealth for HIV prevention and sexual health care among men who have sex with men in China. J Med Internet Res 2015 Apr 21;17(4):e100 [FREE Full text] [doi: 10.2196/jmir.3370] [Medline: 25900881]

49. Lau JT, Gu J, Tsui HY, Wang Z. Prevalence and associated factors of intention to participate in HIV voluntary counseling and testing for the first time among men who have sex with men in Hong Kong, China. Prev Med 2013 Dec;57(6):813-818. [doi: 10.1016/j.ypmed.2013.09.005] [Medline: 24045009]

50. Lau JTF, Li D, Wang Z, Lai CHY. Repeated HIV voluntary counseling and testing increased risk behaviors among men who have sex with men in China: a prospective cohort study. AIDS Behav 2015 Nov;19(11):1966-1977. [doi: 10.1007/s10461-015-1034-x] [Medline: 25863465]

51. Ziebland S, Herxheimer A. How patients' experiences contribute to decision making: illustrations from DIPEx (personal experiences of health and illness). J Nurs Manag 2008 May;16(4):433-439. [doi: 10.1111/j.1365-2834.2008.00863.x] [Medline: 18405260 ]

52. Wengraf T. Preparing lightly-structured depth interviews: a design for a BNIM-type biographic-narrative interview. In: Wengraf T, editor. Qualitative Research Interviewing: Biographic Narrative and Semi-structured Methods. London: Sage Publications; 2001:111-152.

53. Kreuter MW, Holmes K, Alcaraz K, Kalesan B, Rath S, Richert M, et al. Comparing narrative and informational videos to increase mammography in low-income African American women. Patient Educ Couns 2010 Dec;81 Suppl:S6-14 [FREE Full text] [doi: 10.1016/j.pec.2010.09.008] [Medline: 21071167]

54. Ritchie J, Spencer L. Qualitative data analysis for applied policy research. In: Analyzing Qualitative Data. London: Routledge; 2002:187-208.

55. Frank K. Rethinking risk, culture, and intervention in collective sex environments. Arch Sex Behav 2019 Jan 10;48(1):3-30. [doi: 10.1007/s10508-018-1153-3] [Medline: 29748787]

56. van Laer T, Feiereisen S, Visconti LM. Storytelling in the digital era: a meta-analysis of relevant moderators of the narrative transportation effect. J Bus Res 2019 Mar;96:135-146. [doi: 10.1016/j.jbusres.2018.10.053]

57. Brunyé TT, Ditman T, Mahoney CR, Augustyn JS, Taylor HA. When you and I share perspectives: pronouns modulate perspective taking during narrative comprehension. Psychol Sci 2009 Jan;20(1):27-32. [doi: 10.1111/j.1467-9280.2008.02249.x] [Medline: $\underline{19076318]}$

58. Miller-Day M, Hecht ML. Narrative means to preventative ends: a narrative engagement framework for designing prevention interventions. Health Commun 2013 Oct;28(7):657-670 [FREE Full text] [doi: 10.1080/10410236.2012.762861] [Medline: 23980613]

59. de Graaf A. The effectiveness of adaptation of the protagonist in narrative impact: similarity influences health beliefs through self-referencing. Hum Commun Res 2013 Oct 03;40(1):73-90. [doi: 10.1111/hcre.12015]

60. Gao MY, Wang S. Participatory communication and HIV/AIDS prevention in a Chinese marginalized (MSM) population. AIDS Care 2007 Jul 14;19(6):799-810. [doi: 10.1080/09540120601114832] [Medline: 17573601]

61. Wong C, Tang CS. Sexual practices and psychosocial correlates of current condom use among Chinese gay men in Hong Kong. Arch Sex Behav 2004 Apr;33(2):159-167. [doi: 10.1023/b:aseb.0000014330.67201.1b]

62. Gu J, Lau J, Tsui H. Psychological factors in association with uptake of voluntary counselling and testing for HIV among men who have sex with men in Hong Kong. Public Health 2011 May;125(5):275-282. [doi: 10.1016/j.puhe.2011.01.010] [Medline: 21419466] 
63. Occa A, Suggs LS. Communicating breast cancer screening with young women: an experimental test of didactic and narrative messages using video and infographics. J Health Commun 2016 Jul 06;21(1):1-11. [doi: 10.1080/10810730.2015.1018611] [Medline: 26147625]

64. Shaffer VA, Owens J, Zikmund-Fisher BJ. The effect of patient narratives on information search in a web-based breast cancer decision aid: an eye-tracking study. J Med Internet Res 2013;15(12):e273 [FREE Full text] [doi: 10.2196/jmir.2784] [Medline: 24345424]

\section{Abbreviations \\ HIV: human immunodeficiency virus \\ STI: sexually transmitted infections}

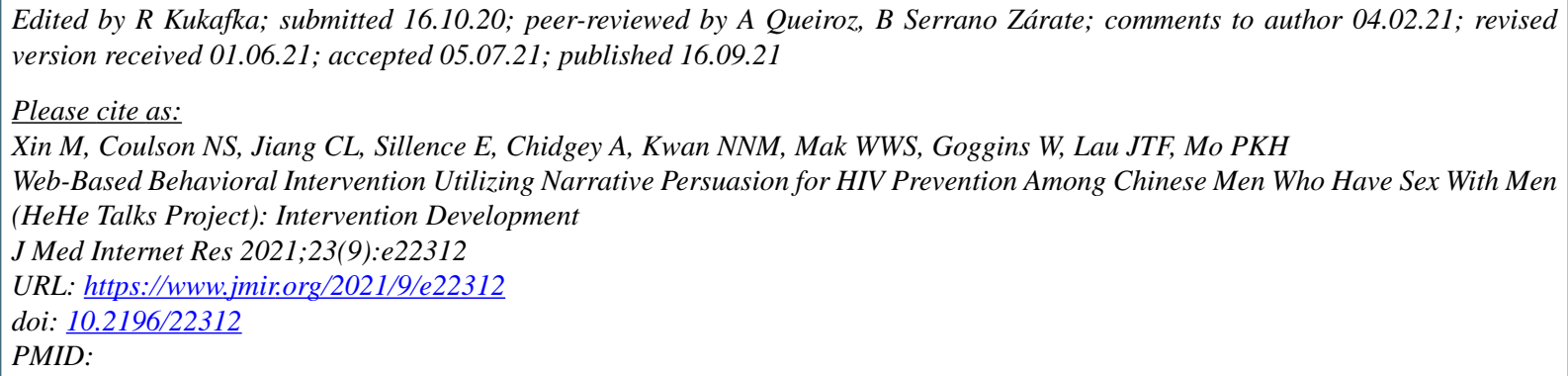

CMeiqi Xin, Neil S Coulson, Crystal Li Jiang, Elizabeth Sillence, Andrew Chidgey, Norman Nok Man Kwan, Winnie W S Mak, William Goggins, Joseph Tak Fai Lau, Phoenix Kit Han Mo. Originally published in the Journal of Medical Internet Research (https://www.jmir.org), 16.09.2021. This is an open-access article distributed under the terms of the Creative Commons Attribution License (https://creativecommons.org/licenses/by/4.0/), which permits unrestricted use, distribution, and reproduction in any medium, provided the original work, first published in the Journal of Medical Internet Research, is properly cited. The complete bibliographic information, a link to the original publication on https://www.jmir.org/, as well as this copyright and license information must be included. 